\title{
TRICHOMONAS VAGINALIS INFESTATION *
}

\author{
By W. GLEN LISTON, C.I.E., M.D., F.R.C.P.(Ed.)
}

[From the Laboratory of the Royal College of Physicians, Edinburgh.]

Trichomonas vaginalis was discovered by Donné rather more than a Ioo years ago. As might have been expected many workers have attempted to study this organism, but little progress was made until quite recent years.

The study of the group of organisms like Trichomonas vaginalis is difficult because of the small size of the organisms, their very delicate structure and their fragility. It is not easy to fix and stain them without causing very serious distortion and even destruction of some of their slender organelles. For this reason divergent views are held regarding the existence and recognition of different species. In these circumstances it is necessary to know something of their morphology.

\section{Morphology of a Trichomonas}

A trichomonas (see Diagram I) has a lozenge-shaped body with a large nucleus, the macro- or tropho-nucleus close to its anterior end ; this macronucleus is oval and has a saccular appearance. Adjacent to it is a collection of minute bodies so closely aggregated as to look like a single body very much smaller than the macronucleus. This aggregation stains in a manner very similar to the macronucleus and is called by some the micro-nucleus or kineto-nucleus ; the more correct name is the blepharoplast. It is connected to the larger nucleus by a very delicate and very short fibre known as the rhizoplast.

Extending outward from the blepharoplast are long hair-like structures capable of active movements and known as flagella. Each flagellum has a central fibre or axoneme, covered by a very thin layer of the substance which makes up the mass of the body of the organism.

* Based on a lantern slide demonstration introducing a discussion at a meeting of the Medical Society for the Study of Venereal Disea ses on April 27th, 1940. 
Each axoneme arises from the blepharoplast. The flagella vary in number in different species and generally extend freely outwards from the body in an anterior direction. One axoneme, however, is more closely bound down to the body, sometimes throughout its whole length,

\section{OrGanelles of a Typical Trichomonas.}

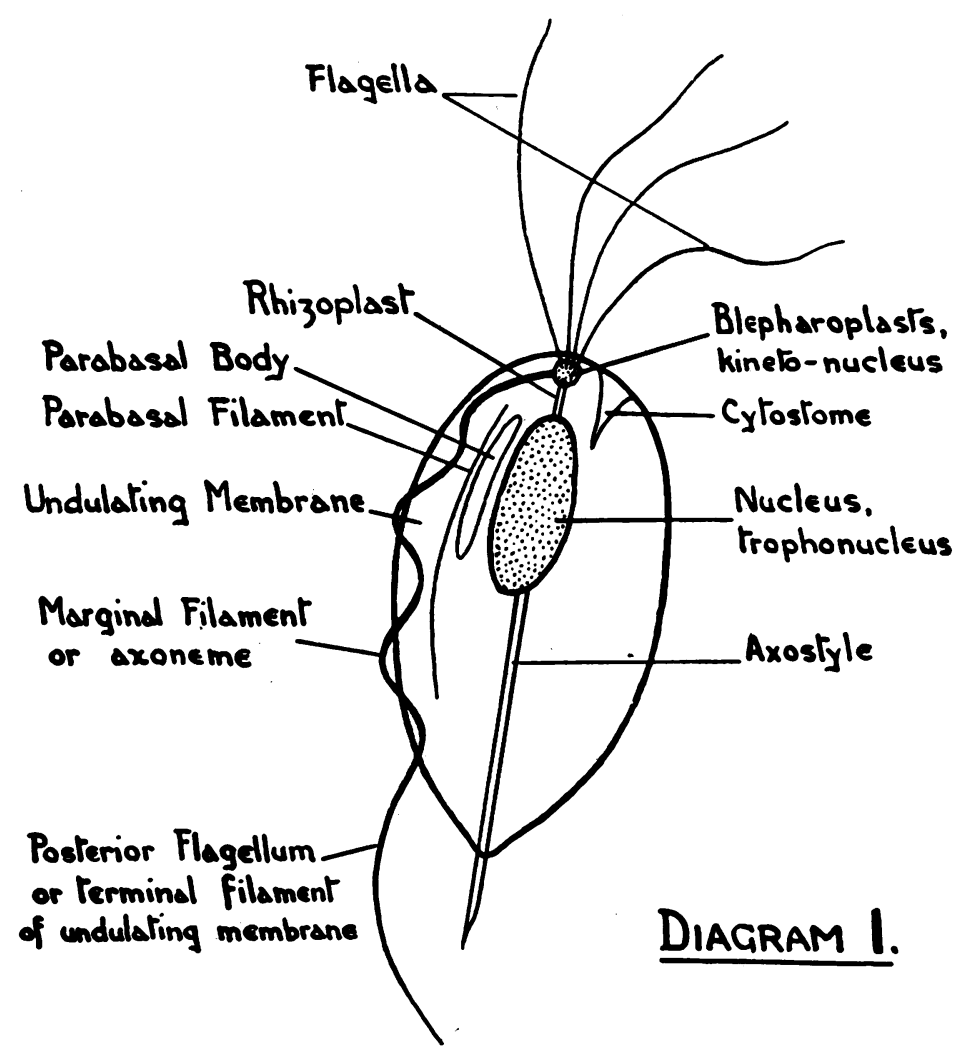

[Reproduced from the Journal of Obstetrics and Gyncecology o; the British Empire, Vol. 46, No. 3, and Vol. 47, No. 2, by permission

by a layer of the material derived from the body, which covers the axoneme. This layer is pulled or stretched out in the form of a thin membrane conterminous with the body of the organism from the blepharoplast anteriorly to a distance posteriorly which varies in different species. The axoneme runs along the outer margin of the mem- 


\section{TRICHOMONAS VAGINALIS INFESTATION}

brane, and it can communicate to the membrane a wavelike motion, hence the name, undulating membrane. In some species of trichomonas the axoneme of the undulating membrane extends beyond the portion of the membrane which is bound down to the body and so forms another flagellum, which in this case is directed posteriorly.

Within the body of the organism extending from the nucleus is a rod-like structure which can be protruded or retracted from the posterior end of the body ; this organ is called the axostyle. When the axostyle is protruded the trichomonas can fix itself to any structure by means of a sticky fluid discharged from its point. When the organism is thus anchored the rhythmical flail-like or whip-like movements of its flagella and the sinuous movements of its undulating membrane generate currents in the liquid medium in which the organism generally lives, and by this means particles of food are drawn towards its body.

When the organism is not fixed by its axostyle it can swim in a liquid medium by means of its flagella and undulating membrane. If the liquid becomes thickened or clogged with cells the trichomonas can make its way through and among the cells by amœboid movements. A trichomonas can by this means penetrate the epithelium of a mucous membrane, and Wenyon (I926) has shown in sections trichomonas under the epithelium of the bowel. It is probable that the small papules which are so characteristic of trichomonas vaginitis and which give to the examining finger in the vagina a sensation of roughness may be caused by the penetration of the parasite below the epithelium.

Some workers have stated that Trichomonas vaginalis is furnished with a mouth, but I have not been able to satisfy myself that such an organ is present. I have often noted that the blepharoplast and flagella appear to be situated on a small papilla or pedicle protruding from the body of the organism when it is viewed in certain positions. This papilla is not unlike a very small nose or lip on which the flagella or "whiskers" are borne. A shallow groove runs down the body just below this lip, and it is in this groove that the flagella end their whiplike stroke; the undulating membrane runs along the edge of the groove. Food is taken into the body much after the manner of an amoba. 
Trichomonas feed with avidity on starch, and individual organisms can be seen in cultures glutted with starch granules, some of which may be as large as the body of a normal-sized trichomonas. These large starch granules could not have been swallowed through a mouth but must have been engulfed as an amœba engulfs its food.

\section{Differentiation of Species}

While morphological differences are important in distinguishing the species it is by no means easy to establish these differences because (I) the organism is so soft and fragile; (2) during multiplication by simple division certain organs, the flagella for example, are duplicated ; (3) in cultures, which are generally required for the determination of species, pathological forms are developed of bizarre shape and size. For these reasons it is necessary to study a very large number of preparations of a particular trichomonas before specific morphological characteristics can be determined. Physiological differences in the species are therefore valuable aids in differentiation. Such physiological differences, as the ability to grow and multiply at a certain temperature or in media of a certain hydrogen ion concentration, are useful in this respect. Objections, however, have been raised to the value of even these differences. It is averred that a particular strain of trichomonas can in time adapt itself to a changed environment, and in this new environment the morphological characteristics of the original strain may be transformed into those of quite another strain (Karnaky, Andrews).

It is impossible to discuss these points in detail here, but various species of trichomonas can be distinguished from one another in the first place by the number of flagella in normal individuals. Thus there are species with respectively three, four and five flagella. The individuals constituting these groups of tri-, tetra- and penta-trichomonas can be distinguished from one another by other morphological points or on the ground of physiological differences. Tritrichomonas cavia and Tritrichomonas foetus (see Diagram 2 and Plate I, Fig. I) for example, each have three flagella. The former species is easily found in the cæcum of guinea-pigs, where it appears to be a harmless parasite. The latter is found in the vagina of certain cows or beneath the sheaths of 


\section{TRICHOMONAS VAGINALIS INFESTATION}

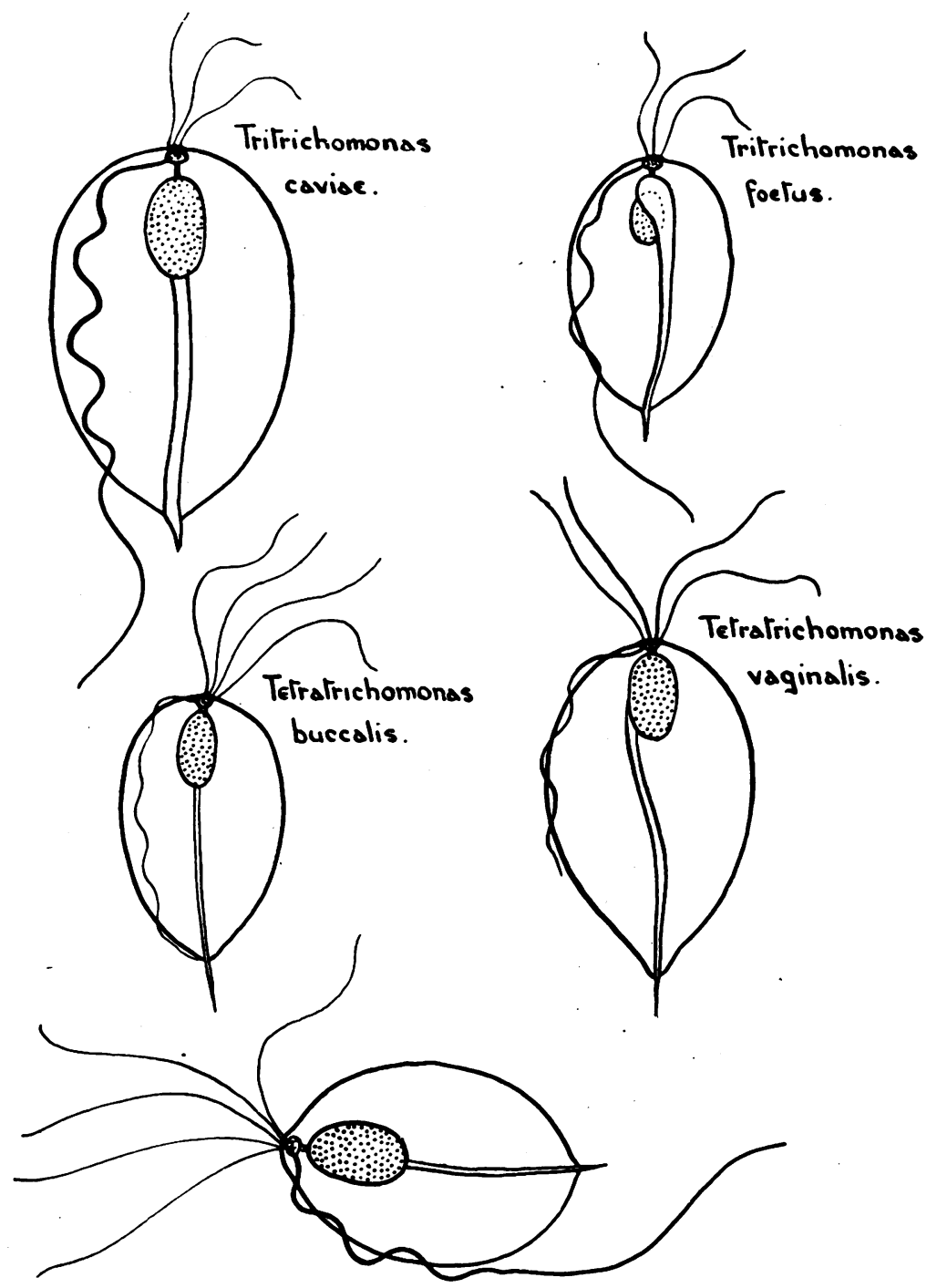

infected bulls, and is well known to be the cause of abortion and sometimes pyometra in cows. It can be transmitted to cows by an infected bull (Stableforth $e t$ 
al.). Tritrichomonas cavia is a much larger organism than Tritrichomonas foetus. Its undulating membrane is a very well-developed structure and its axoneme is strong and powerful and extends beyond the undulating membrane as a posterior flagellum. The trichomonas found in infected cows is a small organism with a more delicate undulating membrane, although, in this case also, the axoneme extends beyond the membrane as a posterior flagellum. The structure of the axostyle in this species is also peculiar to the species (Wenrick and Emmerson).

Two species with four flagella are found in man. Tetratrichomonas buccalis (Goodey and Wellings (Diagram 2 and Plate I, Fig. 2)), which, according to Dobell is more correctly called $T$. tenax, is an inhabitant of the human mouth. Its presence there is possibly of little pathological significance although it has been found in the mouths of persons suffering from congested throat and enlarged tonsils. It has been found also in the mouths of persons with decayed teeth. Tetratrichomonas vaginalis (Powell, Bland) (Diagram 2 and Plate II, Fig. 3) is an inhabitant of the human vagina and, without doubt, is an important cause of leucorrhœa in women. These species very closely resemble one another. Tetratrichomonas vaginalis is, on the average, larger than Tetratrichomonas buccalis; while the latter grows and multiplies easily at room temperature, the former requires a temperature of about $37^{\circ} \mathrm{C}$. These organisms can also be distinguished from one another on morphological points for the undulating membrane in Tetratrichomonas buccalis extends to the end of the body, while in $T$. vaginalis it is bound down to the body for not more than two-thirds of the length of the body. Neither of these organisms has a posterior flagellum. The axoneme of the undulating membrane of $T$. buccalis is very slender. but is rather more substantial in $T$. vaginalis.

A species of trichomonas with five flagella is found in the rectum in about I per cent. of human beings. It has been named Pentatrichomonas arden-delteili by Kofoid (Kofoid, Chatterjee) (Diagram 2 and Plate II, Fig. 4). In living preparations this species very closely resembles Tetratrichomonas buccalis, especially in its size and in its ability to grow and multiply in a suitable culture II8 
PLATE I

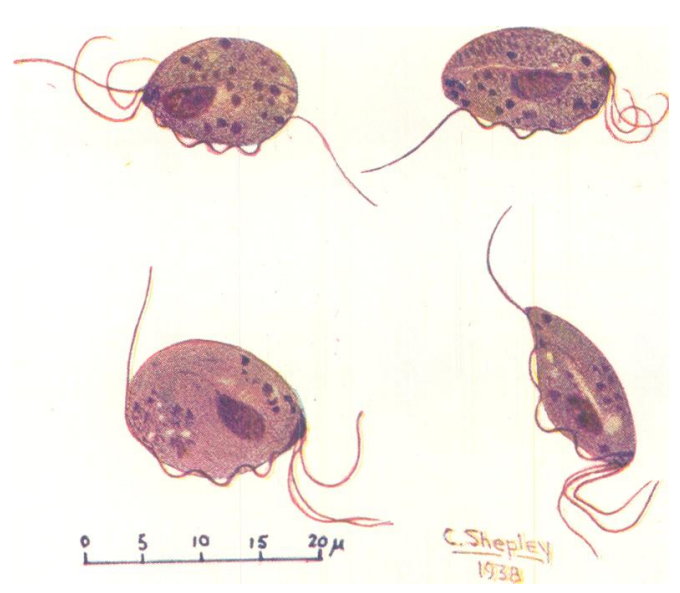

FIG. I.

Tritrichomonas fœetus.
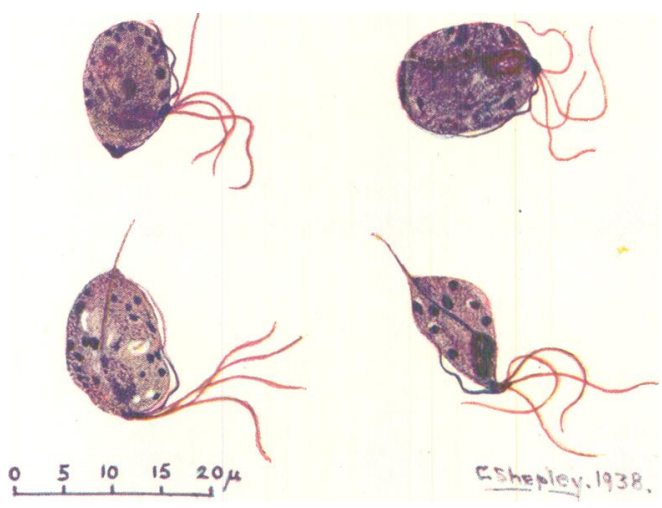

Reproduced from the Journal of Obstetrics and Gyncecolog $y$ of the British Limpire, Vol. $46,$. No. 3 , and Vol. 47 , . No. 2, by permission.

FIG. 2.

Tetratrichomonas buccalis. 
PLATE II
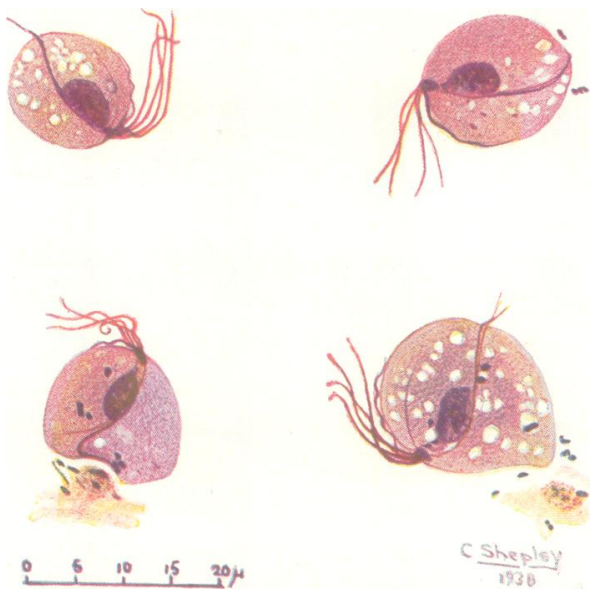

FIG. 3 .

Tetratrichomonas vaginalis.
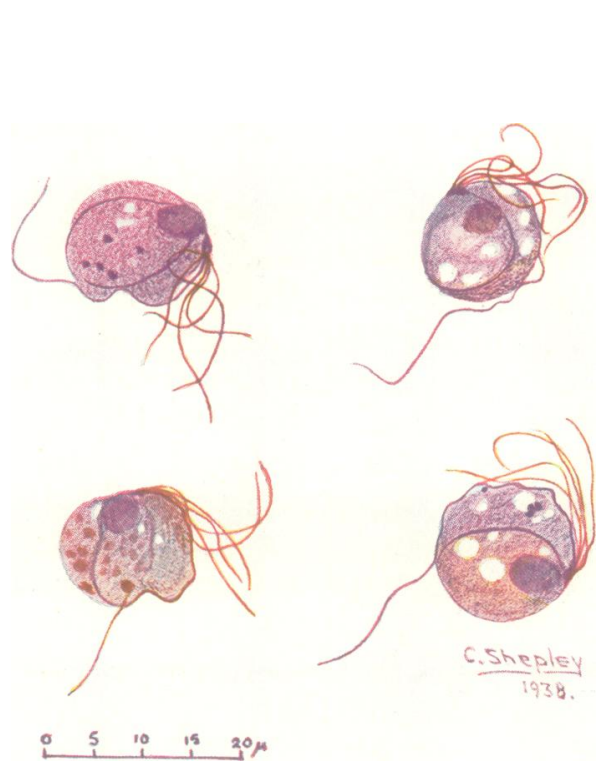

[Reproduced from the Journal of Obstetrics and Gynicoloyv of the British Empire, Vol. 46, No. 3, and Vol. 47, No. 2, by permissiar. FIG. 4 .

Pentatrichomonas arden-delteili. 


\section{TRICHOMONAS VAGINALIS INFESTATION}

medium at room temperature. For this reason the two species have been confused with one another even by skilled protozoologists (Wenyon, Lynch). Properly stained preparations, however, show that the rectal species has a"well-developed undulating membrane, and the axoneme of this membrane extends beyond the attachment of the membrane to the body so as to form a long posterior flagellum; as mentioned, Tetratrichomonas buccalis has no posterior flagellum.

Another species, Trichomonas hominis, has been described ; it inhabits the intestine, but I have not had an opportunity to study it in detail. It may have been confused with Pentatrichomonas arden-delteili, though some reliable workers have differentiated the two species (Kofoid, Chatterjee) ; this, however, is a matter of very considerable difficulty. In the case of two strains which I isolated from the bowels of two patients I experienced great difficulty in deciding whether I was dealing with T. hominis, which is said to have four flagella, or T. ardendelteili, which has five. It was only after examining a very large series of preparations that I came to the definite conclusion that in both instances I was dealing with the latter species.

Considerable controversy has raged around the question of specific differences in trichomonas strains. Clifford Dobell (I934), taking up a somewhat sceptical attitude towards the question of specific differences in certain strains of trichomonas, carried out a long and elaborate series of experiments with a trichomonas which he had found in the intestine of a monkey. In the course of these experiments he succeeded in establishing this species not only in the intestine of other monkeys of the same and different species but also in his own intestine. Moreover, he succeeded in establishing it in the vagina of a monkey. Dobell states that neither he nor the monkeys suffered any inconvenience from the presence of the trichomonas although infection lasted for some years. He thus showed that a single species of trichomonas can live in different species of hosts, monkeys and men, and in different situations, the intestine and the vagina, and that its presence in these situations may not cause any symptoms.

It is evident that certain species of trichomonas are not particular in regard to the medium in which they 


\section{BRITISH JOURNAL OF VENEREAL DISEASES}

grow and multiply, but there can be no doubt that the species of trichomonas which are found in man inhabit specifically selected sites.

\section{The Detection of Trichomonas Infection of the Vagina}

I will confine myself here chiefly to the methods which I have personally found most useful.

There are three fundamental methods of examination : (I) of wet films; (2) of cultures; and (3) of stained films.

The microscopical examination of wet films is the method commonly adopted for detecting trichomonas. In the case of $T$. vaginalis infestation this examination is facilitated by adding to the material to be examined, i.e., pus, etc., a little human serum diluted with saline (approximately one part of serum to ten of saline). This diluting fluid can be improved by adding to it a drop or two of a dilute safranine solution; I have found that safranine is less toxic to $T$. vaginalis than is the more commonly employed methylene blue. Another way of making this type of preparation is to dip a swab in the discharge and stir it in the diluted serum-safranine solution placed on a slide. The fluid on the slide should be covered with a thin cover-glass and examined under a microscope as soon as possible. Care must be taken not to confuse pus cells with trichomonas. The trichomonas are rather larger than pus cells and do not stain, so that they stand out as clear refractile bodies against a stained background. The flagella and undulating membrane should be clearly defined, for some cells, like the trichomonas, remain unstained and may be confused with trichomonas. The wet film is certainly a quick method of making a diagnosis ; it can often be accomplished in a few seconds if the trichomonas are numerous, but the work of a clinic is disturbed in carrying it out unless an assistant is specially detailed to make it.

The examination of cultures is useful, especially when the trichomonas are scanty, provided always that a suitable culture medium is available. Andrew's (I929), Powell's (I936) or some modification of Boeck's medium, as recommended by Dobell and Laidlaw (I926), may be used for cultivating $T$. vaginalis, but in my experience no very satisfactory culture medium has yet been found 


\section{TRICHOMONAS VAGINALIS INFESTATION}

which will allow this organism to grow with certainty. If it is to be cultivated I have found it best to make subcultures at frequent intervals, every six hours or so, for the first day or two, and at longer intervals later. The cultural method is the best for demonstrating trichomonas in the mouth or rectum, for the species found in these situations in men grow easily and it is unnecessary to make subcultures more frequently than every forty-eight hours or even after a longer interval.

The Microscopical Examination of Suitably Stained Films on Glass Slides.-These films can be prepared conveniently in the course of examining a patient. It is necessary only to smear the soiled gloved finger gently over the surface of a micro-slide to obtain a film suitable for diagnostic purposes. Alternatively a swab or a cigarette paper may be dipped in the purulent discharge and then gently passed over the surface of a slide. The slides must be scrupulously clean and free from oil or grease on the surface. This is best accomplished by wiping them with a clean duster and passing them through the flame of a Bunsen burner. Better films are made if the slides are still warm (they must not be too hot) after being passed through the flame, or if immediately the films are made the slides are placed for a few seconds on a warm surface, such as the cover of a steam steriliser, so that the films dry rapidly.

The purulent discharge may be thinned by adding to it a little dilute serum. Very thin films give the best details in stained specimens but require longer search. One film should be stained with Leishman's stain, while the other is treated by Gram's method. A good brand of Leishman's powdered stain must be used. The stain is conveniently put up in the form of small tablets * each of which contains $0 \cdot 15 \mathrm{~g}$. of the stain, and it is convenient to dissolve six tablets in 60 c.c. of pure methyl alcohol ; the tablets may be ground to a powder before being placed in the alcohol, and the bottle containing the stain should be well shaken to dissolve the stain. It improves with keeping if stored in a glass-stoppered bottle. About I c.c. of the stain is dropped upon the surface of the film and allowed to act on the film for one minute to fix it. Then about $I \frac{1}{2}$ c.c. of distilled (not tap) water are added

* Suitable tablets are procurable from Geo. T. Gurr, I36 New King's Road, London, S.W.6, or soloids from Burroughs Wellcome \& Co.

I2I 
drop by drop to the stain on the film, and stain and water are thoroughly mixed, by drawing the stem of the pipette or a platinum wire through the mixture just above the surface of the slide. The film covered with the diluted stain is allowed to stand for ten to fifteen minutes. The stain is then washed off the film with a stream of distilled water and some of the distilled water is left in contact with the film for a few minutes; the slide may be gently rocked at this time so as to help to extract any excess of stain. The film is again washed in distilled water and placed on end to dry in the air. When dry a drop of Gurr's neutral mounting medium is placed upon the film and this is followed by a cover-glass.

The staining method has the advantage over other methods for detecting trichomonas in that the examination can be made at leisure in a laboratory. Also the slides can be sent to a laboratory by the clinician if he is unwilling or unable to make the examination for himself. In stained films it is unnecessary for purposes of diagnosis to demonstrate all the organelles as in Diagram I or the flagella as in the coloured drawings. Undistorted forms of the parasite are seldom found unless very special arrangements are made and much care is taken in the preparation of the films, but with a knowledge of the morphology of the parasite it is possible to recognise a trichomonas even when it is badly fixed and stained. The body of the organism is stained a light blue colour with Leishman's stain. It may have a very irregular outline, or when better fixed it may be of a lozenge shape. It is generally larger than a pus cell and its very characteristic oval nucleus situated towards the anterior end of the body is stained a reddish purple or magenta colour. These characteristics suffice for recognition of this parasite in a discharge when the examination is made by an experienced person. Nevertheless confirmatory evidence should always be sought by looking for the blepharoplast or micro-nucleus lying close to the macronucleus, possibly connected to it by the rhizoplast. Then better prepared specimens may reveal some of the flagella or the undulating membrane or even the axostyle (see Plate IV, Fig. 8). With a little practice the parasites are easily recognised under a low magnification, such as a $\frac{1}{4}$ inch objective, and when they are few in number they are more easily found in this way. 


\section{TRICHOMONAS VAGINALIS INFESTATION}

\section{The Distribution of T. Vaginalis in Nature}

It is remarkable that $T$. vaginalis has never been found free in nature. As a parasite it is strictly confined to man. There is no evidence to prove, for example, that swimming baths are a source of infection although this has frequently been asserted. Nor has any resistant form of the parasite been detected. False spores or cysts have been described, but true cysts have not been found in $T$. vaginalis ; cyst forms, however, are known to be produced by certain other species of trichomonas. It is in these circumstances puzzling to know how infection is spread. Intimate contact sometimes results in infection, as, for example, when an uninfected girl sleeps in the same bed with an infected one. Such cases, however, are rare. More frequently women acquire infection without any known contact with an infected case. Carrier cases, persons infected but who show very little evidence of infection, are numerous, and these may be a fruitful source of infection.

It will be shown that a certain reduction of acidity of the vagina favours the development of $T$. vaginalis. The normal healthy vagina is too acid for it, but this natural protective mechanism is upset during the menstrual period, when the vagina becomes less acid and then infection may readily occur. Possibly the use of soiled sponges or washing cloths at this time might transmit infection. I have seen a number of cases who dated their infection from a period when they were resident in hospital for an operation, and I have also been struck by the number of cases I have seen among waitresses and shop girls, communities where it seems possible that soiled washing cloths or towels might spread infection. When present as a parasite in women $T$. vaginalis confines itself almost entirely to the vagina. In rare cases the parasite may be found in the cervical canal, especially when the condition is complicated by a gonorrhœal infection. The organism is much more frequently found in the urethra, whether with or without an accompanying gonorrhœal infection. Frequency of micturition is therefore one of the common complaints of patients suffering from trichomonas vaginitis. The parasite may pass by way of the urethra to the bladder and thus cause cystitis (Nitschke). A further extension of the infestation of the urinary tract may cause pyelitis (Lewis and Carroll ; Visher). 
Males may become infected from females suffering from trichomonas vaginitis (Liston and Lees). These infected males may infect or reinfect females. In male subjects the organism is usually found beneath the prepuce or in the anterior part of the urethra. In a smaller number of male subjects Trichomonas vaginalis may establish itself in the. posterior urethra. From this point the organisms may advance either along the urinary or the genital tract. The bladder and kidneys may be invaded (Rosenthal), or the prostate, seminal vesicles and testes (Liston and Lees). If the infection persists for a time in the posterior urethra a stricture may develop (Cornell and Riba).

It may be said, generally, that Trichomonas vaginalis does not find a very suitable habitat in the male urethra and the symptoms caused by its presence there are generally trivial ; the trichomonas soon disappear and a cure is effected. But when infestation persists, possibly after repeated reinfections, as in the case of a husband with a wife suffering from trichomonas vaginitis, the organism may establish itself in this unusual situation. Eradication then becomes difficult and serious symptoms may develop. Trichomonas vaginalis in these circumstances may penetrate the tissues by amœboid movements in the manner described and thus take up an abode in and below, rather than on, the surface of mucous membranes. In these circumstances it becomes very difficult to demonstrate the presence of the parasite in the discharges. The fact that these later lesions are due to Trichomonas vaginalis has often to be inferred from the previous history of the case and the finding of the parasite in the early stages of the disease, when it still lived upon the surface of the mucous membrane. Some workers state that they have found trichomonas in the blood of patients suffering from trichomonas vaginitis (Wagner and Hees), but I hesitate to accept these findings, inasmuch as the drawings of the organisms which were detected in the blood did not represent Trichomonas vaginalis but some other trichomonas which may have contaminated the films or cultures used by these workers. As mentioned, the normal habitat of $T$. vaginalis is the vagina, and accounts of its having been found elsewhere than here or in the urethra must be regarded with reserve. 


\section{TRICHOMONAS VAGINALIS INFESTATION}

\section{Conditions Favouring the Growth and Development of $T$. vaginalis in the Vagina}

A film of the normal adult vaginal contents between menstrual periods, when stained by Gram's method, shows some large epithelial squares, one or two pus cells and a large number of long Gram-positive bacilli known as Doederlein's. Besides this there are recondite characteristics of importance in regard to infestation with $T$. vaginalis ; for example, the presence of much glycogen in the epithelial cells and an acid condition which can be measured as a $p \mathrm{H}$ of about 4 .

The presence of glycogen in the epithelial cells can be revealed by staining a film by Best's carmine method which shows the majority of the epithelial cells crammed with carmine-stained glycogen.

Glycogen is not deposited in the epithelial cells of the vagina at all periods of life (Cruickshank and Sharman). At birth the epithelial cells of the vagina are full of glycogen, but these glycogen-containing cells are shed and discharged within the first week or two after birth. In a section of the vagina of a baby one week old which was stained by Best's carmine method, the epithelial cells of the vagina were filled with carmine stained granules, but these cells were evidently being shed into the vagina. After the first month of life till puberty is attained glycogen is not found in the epithelial cells of the vagina. At puberty glycogen is again deposited in the epithelial cells of the vagina, and it continues to be stored there for some years after the menopause. The deposition of glycogen in the epithelium of the vagina has been connected with the presence of œestrogenic substances in the body, derived in the case of the baby from the maternal circulation and therefore soon lost after birth, but generated intrinsically at puberty till some time after the menopause. In this connection it is interesting to note that Trichomonas vaginalis is found only in adult females ; children before puberty do not suffer from this parasite and women some years after the menopause are not often infected. The presence of glycogen in the vaginal epithelium seems to be necessary for the development of the parasite. There are two possible explanations for this requirement of glycogen by $T$. vaginalis. First there are grounds for believing that this organism feeds 


\section{BRITISH JOURNAL OF VENEREAL DISEASES}

upon glycogen, secondly glycogen is required, as will be explained presently, to maintain a certain degree of acidity of the vaginal contents favourable for the development of the organism.

In support of the first of these explanations, a film from the vagina of a patient suffering from trichomonas vaginitis may show many of the epithelial cells deprived of their glycogen and evidence that the trichomonads were feeding on it by the presence in them of minute granules of the glycogen stained red by the carmine ; in this way they are in fact easily distinguished from the pus cells in the film. In view of the technical difficulties of staining films by Best's method, I have confirmed the fact of the glycogen being taken up by trichomonas by testing them with iodine. I found that some trichomonas stained a deep brown colour, as do epithelial cells containing glycogen when treated in this way. The presence of glycogen in trichomonas is not easily demonstrated in specimens made directly from the vagina. Glycogen is more clearly revealed in a specimen made from a saline emulsion of the vaginal contents which has been standing at room temperature for some hours.

As regards the relation of glycogen to the degree of acidity required by $T$. vaginalis, the acidity of the vagina in adults is normally dependent on the production of lactic acid from glycogen by the action of Doederlein's bacillus (Cruickshank). In children and old women the vagina has a neutral reaction, approximating $p \mathrm{H} 7$, because no glycogen is present in the epithelial cells. Such persons are never infected with $T$. vaginalis.

It has long been known that the character of the bacterial flora found in the vagina depends on the degree of acidity of the vaginal contents. Thus in I9I4 Heurlin drew attention to this interdependence and proposed a classification of the bacterial flora found in the vagina based upon the acid state of the vagina under varying conditions. Other workers (Schultheiss; Ganssle) confirmed and modified Heurlin's classification so that the bacterial flora of the vagina is now recognised to consist of three types depending on the amount of acid present in each case.

Type I (Plate III, Fig. 5) consists of an almost pure culture of the large Gram-positive Doederlein's vaginal bacillus. This organism is found in the vagina when 

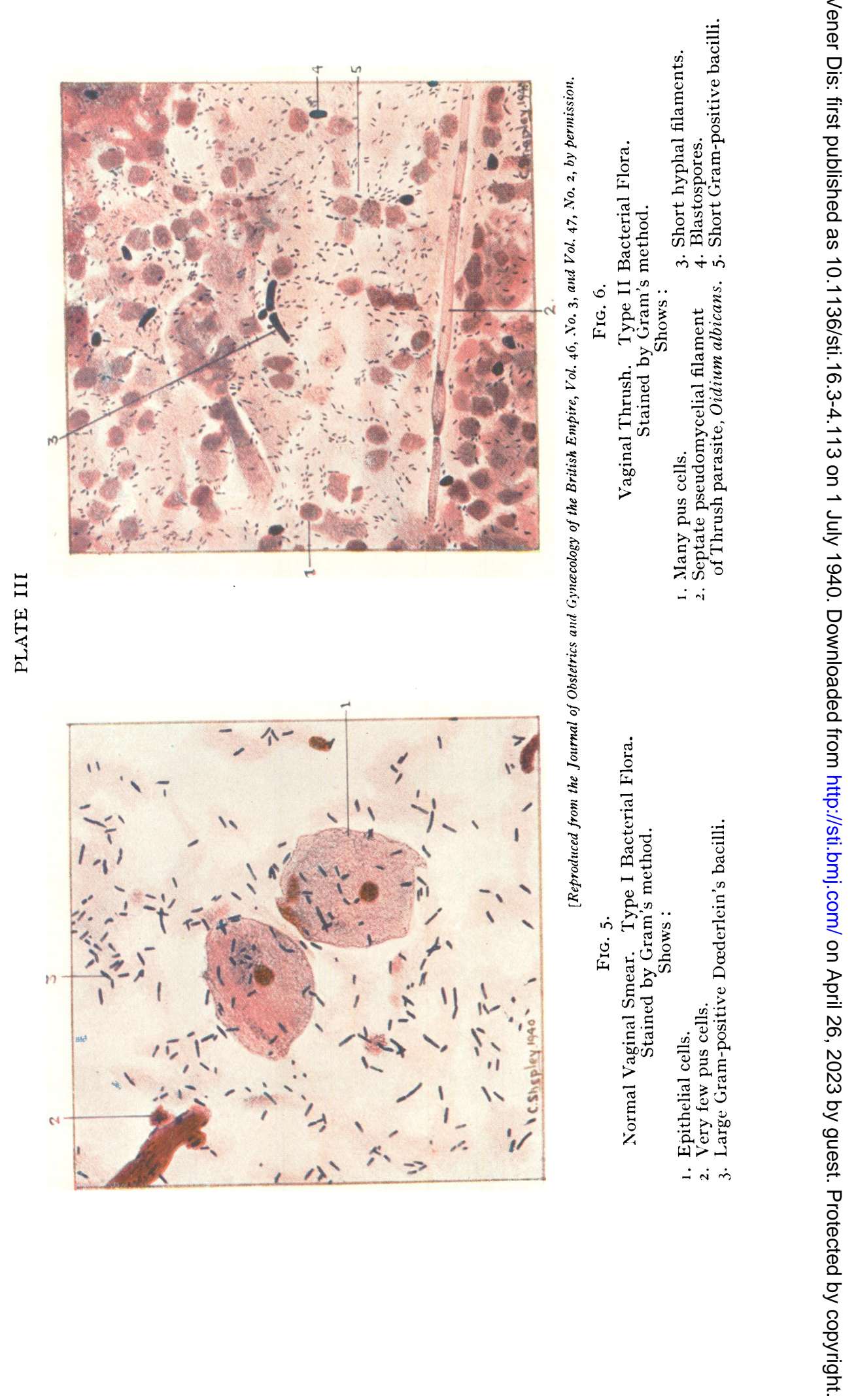

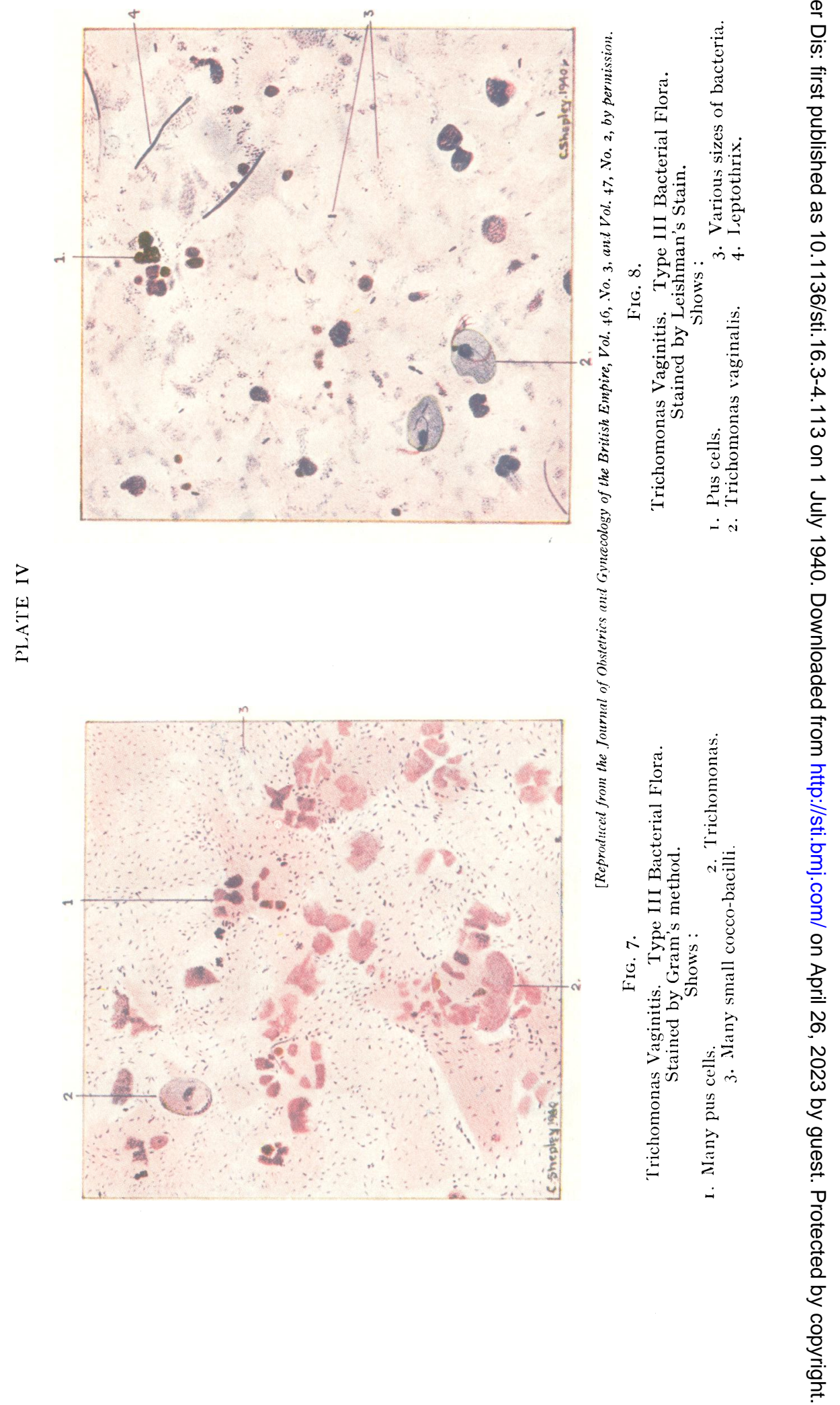


\section{TRICHOMONAS VAGINALIS INFESTATION}

the highest concentration of acid is present in it, as occurs in healthy adult females; disease-producing parasites are seldom associated with it. It has been proved that very few organisms other than Doederlein's bacillus can thrive in such a high concentration of acid. Occasionally, however, the thrush fungus and still more rarely $T$. vaginalis may be found together with Doederlein's bacillus in the vagina. In these circumstances there is always some slight reduction in the acidity of the vaginal contents below the ideal normal which can be measured as a $p \mathrm{H}$ of between $3 \cdot 8$ and 4 .

Type II (Plate III, Fig. 6) consists mainly of Grampositive bacilli rather smaller in size than Doederlein's bacillus and resembling that class of bacteria known as diphtheroids. They are found in the vagina when the concentration of lactic acid is somewhat lower than that which is suitable for Doederlein's bacillus. A greater variety of organisms may be present in the vagina in these circumstances including sometimes a few Gramnegative bacilli. The thrush fungus, Oidium albicans, is often associated with a Type II flora, as a concentration of acid which favours the organisms grouped under Type II favours also the growth of this parasite. $O$. albicans is recognised microscopically in Gram-stained films by the finding of the long septate pseudo-mycelium together with the yeast-like blastospores derived from the mycelium by budding. $T$. vaginalis is also sometimes associated with this Type II flora but not in large numbers because the acidity of the vaginal contents which suits a Type II flora is not ideal for T. vaginalis.

Type III flora (Plate IV, Figs. 7 and 8) is found in vaginæ in which still less acid is present. This type of flora comprises a great variety of organisms but small coccobacilli preponderate. Many of these organisms are Gramnegative, contrasting with the Gram-positive organisms which preponderate in the other two types of vaginal flora. Spirochætes and leptothrix may also be met with.

It is in association with a Type III flora that $T$. vaginalis is at home as the degree of acidity favourable for them favours also $T$. vaginalis.

It is evident then that the type of flora present in the vagina may portend the presence of $T$. vaginalis. The less acid condition of the vagina connected with a deficiency of glycogen in the epithelial cells and associated 


\section{BRITISH JOURNAL OF VENEREAL DISEASES}

with a Type III bacterial flora favours the development of $T$. vaginalis, and a high concentration of lactic acid and abundant glycogen in the epithelial cells associated with Type I flora (features present in the vagina of normal adult females) are inimical to its growth and development.

While thus the type of bacterial flora found in the vagina can be used as a rough gauge of the acidity it is better to measure it more accurately. It is usual to express the acidity of a solution in terms of hydrogen ion concentration, or more conveniently by a $p \mathrm{H}$ or hydrogen ion exponent, and a fluid with a $p \mathrm{H} 7$ at $22^{\circ} \mathrm{C}$. is regarded as neutral. If the $p \mathrm{H}$ is less than 7 the fluid is acid; if it is greater than 7 it is alkaline. The $p \mathrm{H}$ of the vagina in varying circumstances lies between 4 and 7 .

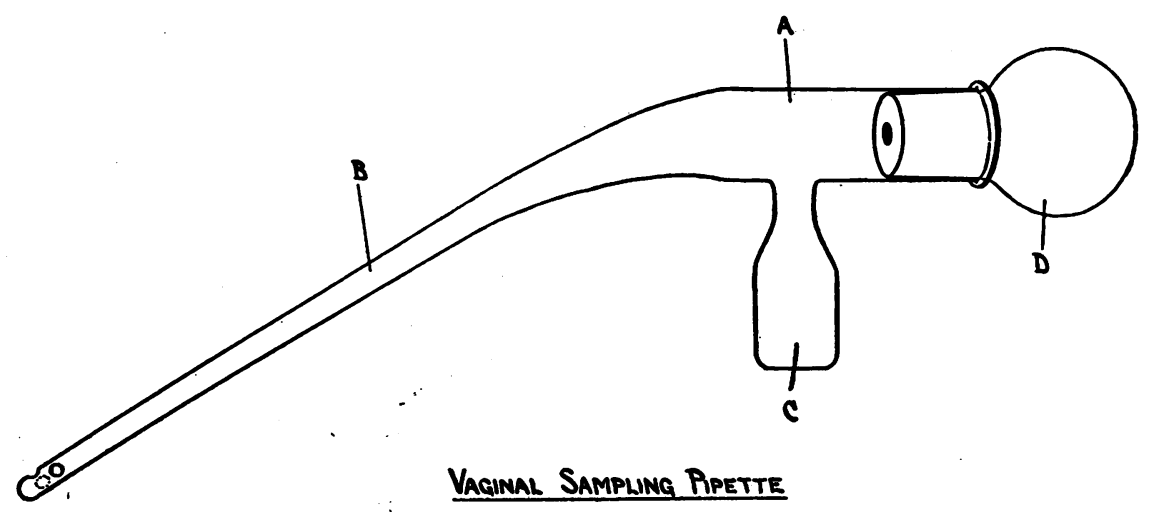

[Reproduced from the Journal of Obstetrics and Gynacology of the British Empire, Vol. 46, No. 3, and Vol. 47, No. 2, by permission.

A fall from a $p \mathrm{H} \eta$ to $p \mathrm{H} 4$ means that the hydrogen ion concentration is 1,000 times greater. Many biological processes are influenced by the hydrogen ion concentration of the environment and the growth and development of $T$. vaginalis in the vagina is no exception to this rule. The progress of a case of trichomonas vaginitis towards cure can be followed by observations on the hydrogen ion concentration of the vaginal contents. Recovery runs parallel with a fall in the $p \mathrm{H}$ towards 4 , or in other words with an increase in the acidity of the vaginal contents to normal.

I have tried different ways of measuring the $p \mathrm{H}$ of the vaginal contents as advocated by certain workers but have not succeeded in obtaining consistent readings when repeated either by myself or with the assistance of others. I believe much that has been written regarding 


\section{TRICHOMONAS VAGINALIS INFESTATION}

the $p \mathrm{H}$ of the vaginal contents may require revision. I have however read a very helpful and instructive paper on this subject by Oberst and Plass. These workers tested the effects of diluting the vaginal contents with I5 c.c. of neutral distilled water. They compared the $p \mathrm{H}$ of the diluted discharge with the $p \mathrm{H}$ of an undiluted specimen in eighteen instances and found little difference in the two readings. With the assistance of Dr. Kermack I have confirmed this work and found that when the vagina is washed out with 5 c.c. of neutral normal saline solution the $p \mathrm{H}$ of the wash differs very little from that of the undiluted vaginal contents. Thus all that is required to measure the $p \mathrm{H}$ of the vaginal contents is a convenient means of washing out the vagina with sterile neutral saline solution and collecting the material. With this object in view I have invented an instrument which I call a vaginal pipette. It is made from an ordinary test-tube of $\frac{3}{4}$ inch in diameter. The tube $A$ is heated in a blow-pipe flame at a point almost 3 inches from the mouth of the tube and when suitably softened by the heat it is drawn out into a narrower portion or stem, $\mathrm{B}$, about 6 inches long. The stem tapers gradually from the $\frac{3}{4}$ inch diameter of the tube to a diameter of $\frac{3}{16}$ inch at the extremity of the stem. The stem is slightly curved downwards and is closed and rounded off at the point. A capsule, $\mathrm{C}$, or bulb, capable of containing rather more than 5 c.c. of fluid, is blown and annealed at a right angle to the tube at a point about $I \frac{1}{2}$ to 2 inches from the mouth of the tube. The cavity of the capsule opens into the test-tube by a narrow mouth. When the tube is held in a horizontal position with the capsule hanging down three small holes are blown near the distal extremity of the stem, one hole on either side and one dorsal. The capsule, $\mathrm{C}$, can be filled through the mouth of the tube, A, with 5 c.c. of sterile normal saline at a $p \mathrm{H}$ of 7 . An india-rubber bulb, $\mathrm{D}$, is inserted into the mouth of the test-tube. The pipette is then ready for use.*

\section{Examination of Female Patients for Trichomonas Infection}

The patient is placed upon the operating table in the lithotomy position. A careful examination of the vulva

* Half a dozen of these pipettes with bulbs and oak stand to hold them can be purchased from Peter Stevenson Ltd., 7 Forrest Road, Edinburgh. Price 23s. 
is made for evidence of dermal lesions. The labia minora are next separated and examined, particular attention being paid to the openings of Bartholin's ducts. The urethral meatus is then wiped clean with several pledgets of dried wool and the urethra stripped against the pubis with the right index finger in the vagina. Any discharge expressed is collected and two smears are made on separate slides. A bivalve speculum is then introduced into the vagina, care being taken that there is no lubricant or antiseptic solution on its surface. The cervix is next clearly identified and two vaginal smears are made from the posterior fornix.

If an immediate diagnosis is required wet films may be prepared in the manner already described using dilute serum safranine solution.

The vaginal pipette is now taken in hand. Grasped by the bulb the stem is introduced through the speculum. The capsule containing the 5 c.c. of saline solution is at this stage hanging vertically downwards while the point of the stem reaches into the posterior fornix. In this position in the vagina the pipette is rotated on its long axis through an angle of 180 degrees so that the capsule now occupies a position vertically above the body of the pipette. The contents of the capsule are thus spilled into the body and stem of the pipette. Pressure on the bulb will now squirt the saline solution into the vagina. The fluid can be drawn back again into the pipette by relaxing the pressure on the bulb while the point of the stem is immersed in the pool of fluid which collects in the posterior fornix of the vagina. This operation is repeated two or three times till the vagina has been well washed by the saline solution, after which the pipette is once again rotated through an angle of I8o degrees so that the capsule is lowest. Then by compressing and relaxing the bulb most of the fluid can be sucked back into the pipette and it will collect in the capsule which soon becomes filled if no fluid is inadvertently lost.

After the pipette has been withdrawn from the vagina any fluid in the stem of the pipette can be induced to flow into the capsule if the stem is elevated and the bulb is gently tapped with a finger. When the identification number of the case has been marked upon the pipette with a glass pencil or upon a label fixed to the 


\section{TRICHOMONAS VAGINALIS INFESTATION}

body of the pipette it may be placed in a stand till its contents can be examined conveniently.

Meanwhile the vagina is cleaned up with wool pledgets and the external os cleansed of any protruding mucus or pus. Two endocervical smears are next made on separate slides. It is of the utmost importance that the cervical smears be taken from the endo-cervix uncontaminated by vaginal secretion.

If immediate treatment is decided upon as the result of the examination of a wet film this can now be applied, or the patient may be told to report again after the examination of the specimens which have been collected.

When the clinic is over the contents of the vaginal pipettes can be examined while the films upon the microslides are being stained, one set from each situation by Gram's method, the other set with Leishman's stain as has been described.

The contents of the capsule of the pipette will have separated by this time into two parts, a supernatant relatively clear fluid and a sediment of epithelial cells, pus, mucus, etc. The relative proportion between these two parts gives a good indication of the amount of discharge present in the vagina.

The colour and character of the discharge should be noted. A white, rather scanty, deposit is generally found in normal cases. An abundant yellowish creamy deposit is a feature of trichomonas vaginitis. A good deal of mucus is present in cases suffering from cervicitis. A curdy, rather abundant, white deposit is a feature of vaginal thrush.

The hydrogen ion concentration of the supernatant fluid in the pipette is first estimated. This may be done either by a colorimetric method or it may be measured electrometrically. A very convenient colorimetric test of the hydrogen ion concentration of a fluid has been devised by the British Drug Houses Ltd. It is known as the capillator method and has been described fully in a pamphlet published by the British Drug Houses Analytical Laboratories entitled " $p \mathrm{H}$ Values: What they are and how to determine them." This pamphlet can be obtained on application to the firm and should be carefully studied. The capillator method has been used by some workers without a full knowledge of the requirements for obtaining an accurate reading. With due 
care and attention to details it is a relatively simple and inexpensive way of measuring the $p \mathrm{H}$ value of the vaginal contents and so of following the progress under treatment of a case of trichomonas vaginitis. I used it CASES

20

15

10

5

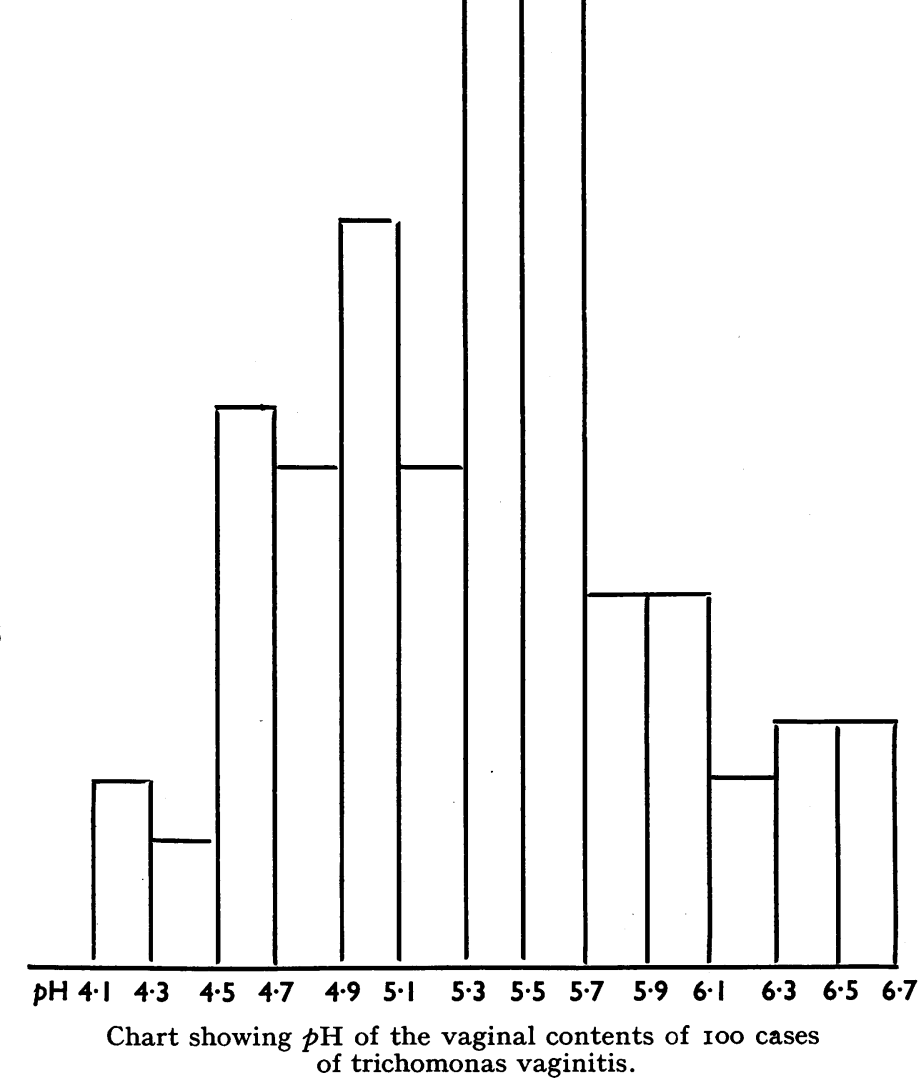

in my early observations but later controlled my findings by employing an electrometrical method; the results of the examinations by both methods closely agreed (Liston and Cruickshank). Lately I have used the electro- 


\section{TRICHOMONAS VAGINALIS INFESTATION}

metrical method alone because of its easy and rapid application. In using Beckman's direct reading $p \mathrm{H}$ meter fitted with a glass electrode all that is required, apart from attention to certain minor details and the regular use of control standard buffered solution, is to pour about 2 to 3 c.c. of the supernatant fluid into a small glass vessel supplied with the instrument and to immerse the glass electrode in the fluid. By pressing a knob and adjusting a needle to the zero mark the $p \mathrm{H}$ of the fluid is read off on another dial, the whole operation taking only a few seconds. Unfortunately the Beckman instrument is expensive ; it has however many uses for biological work.

I have taken $p \mathrm{H}$ readings on a large number of cases of trichomonas vaginitis, and the chart displays in graphic form the findings obtained in Ioo consecutive ones. The majority of these readings were made on new cases; some, however, were made on cases under treatment and were therefore readings on cases in various stages of progress towards recovery. In all the cases $T$. vaginalis was present in the vagina at the time the examination was made. The mean $p \mathrm{H}$ reading of the Ioo examinations was 5.34. Thirty-five of the examinations gave a reading between $5 \cdot 3$ and 5.7 , while 60 of them lay between 5 and 6 .

After the $p \mathrm{H}$ of the supernatant fluid has been recorded the deposit is examined. This examination is carried out with a fourfold object: (I) to determine the extent to which glycogen is deposited in the epithelial cells ; (2) to note the character of the cellular elements present in the vagina, in particular the relative proportion between pus cells and epithelial cells, and the presence of unusual cellular elements, for example, spermatozoa; (3) to look for any parasites, in particular $T$. vaginalis and the thrush fungus $O$. albicans; (4) to note the character of the bacterial flora. Two preparations are required for this examination and they are obtained by placing a drop of the sediment upon each of two micro-slides.

A drop of Lugol's iodine solution, to which a little glycerine has been added, is placed upon and mixed with one of the drops of the sediment. Iodine gives a dark brown colour to glycogen and if this is abundantly present in the epithelial cells in the deposit, the mixture with iodine will assume a dark chocolate brown colour. When less glycogen is present the colour grades in 


\section{BRITISH JOURNAL OF VENEREAL DISEASES}

proportion to the quantity of glycogen from a light golden brown to a light yellow. In the latter case very little glycogen will be found to be present. This is a useful naked eye test for estimating the amount of glycogen in the vaginal contents.

When a cover-slip has been placed upon the mixture it can be examined under the microscope. With a magnification of about 250 diameters some of the epithelial cells are seen to be deeply stained, while others contain less or none of the brown glycogen (Plate V, Fig. 9). The brown colour is concentrated chiefly around the nucleus which remains unstained but may be obscured by stained glycogen around it. In many cases the whole cell is filled with the brown-stained glycogen.

Under a lower magnification (Plate V, Fig. Io), about seventy diameters, a more extensive view of the cellular elements in the deposit may be obtained. In normal healthy females most of the material in the field is seen to consist of epithelial cells crammed with glycogen. Very few pus cells are noted.

In certain abnormal states, in a case of vaginal thrush for example and in certain cases with a cervical erosion, pus cells will be seen to be mixed with the epithelial cells. The relative proportion between the pus cells and epithelial cells is a rough measure of the severity of the inflammatory process associated with the condition. Many of the epithelial cells may have a dark brown colour because of the action of the iodine on the glycogen they contain. But there may be a few or even many epithelial cells not so deeply stained (Plate VI, Fig. II).

In a preparation made from a case of trichomonas vaginitis many pus cells will be present in addition to the epithelial cells and these will be found to contain little or no glycogen (Plate VI, Fig. I2). Indeed a characteristic feature of trichomonas vaginitis is the deficiency of glycogen in the epithelial cells. This is at least one explanation for the relatively high $p \mathrm{H}$ found in this condition, for as we have seen the acidity of the vagina depends on the production of lactic acid from glycogen by the action of Doederlein's bacillus.

The second preparation is secured by adding to the other drop of sediment on the other slide a little dilute serum safranine solution. After mixing a cover-glass is applied and the preparation is examined as a wet film 


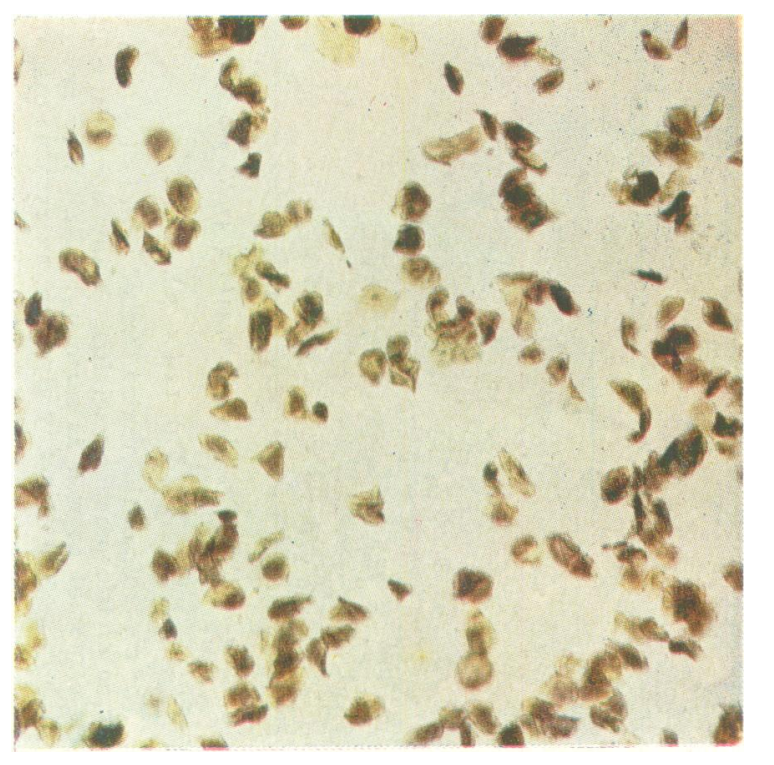

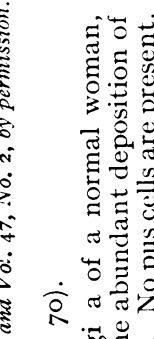

की

$\times$ हुํำ

$0>0$

.

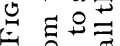

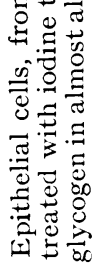

$\underline{\underline{w}}$

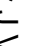

D

믐.

$\overrightarrow{\bar{F}}$

음

产
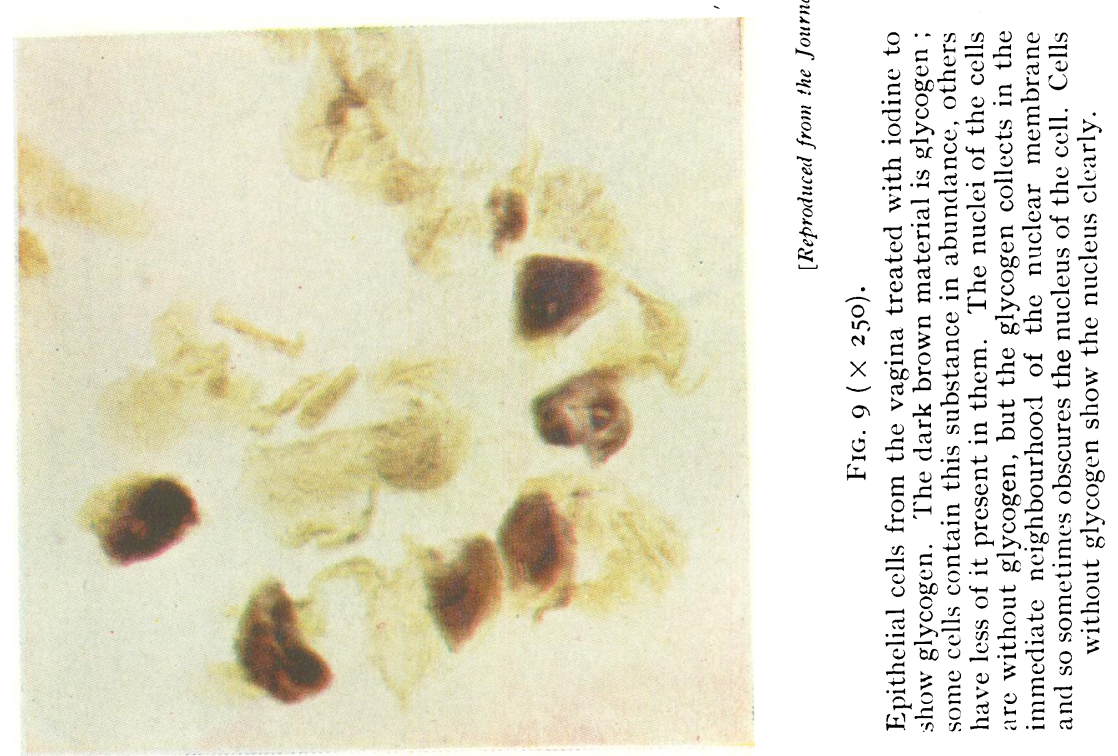

क

$\vec{\circ}$

$\vec{\omega}$

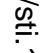

$\vec{\sigma}$

cu

$\vec{\omega}$

윽

产

$\overrightarrow{0}$

o

뭉

בั

政

ํํำ

$\frac{0}{\mathbb{D}}$

홍

粂

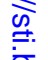

호․

옳

오

을.

N

ก

స్ట

श

뭉

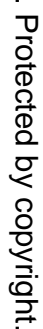



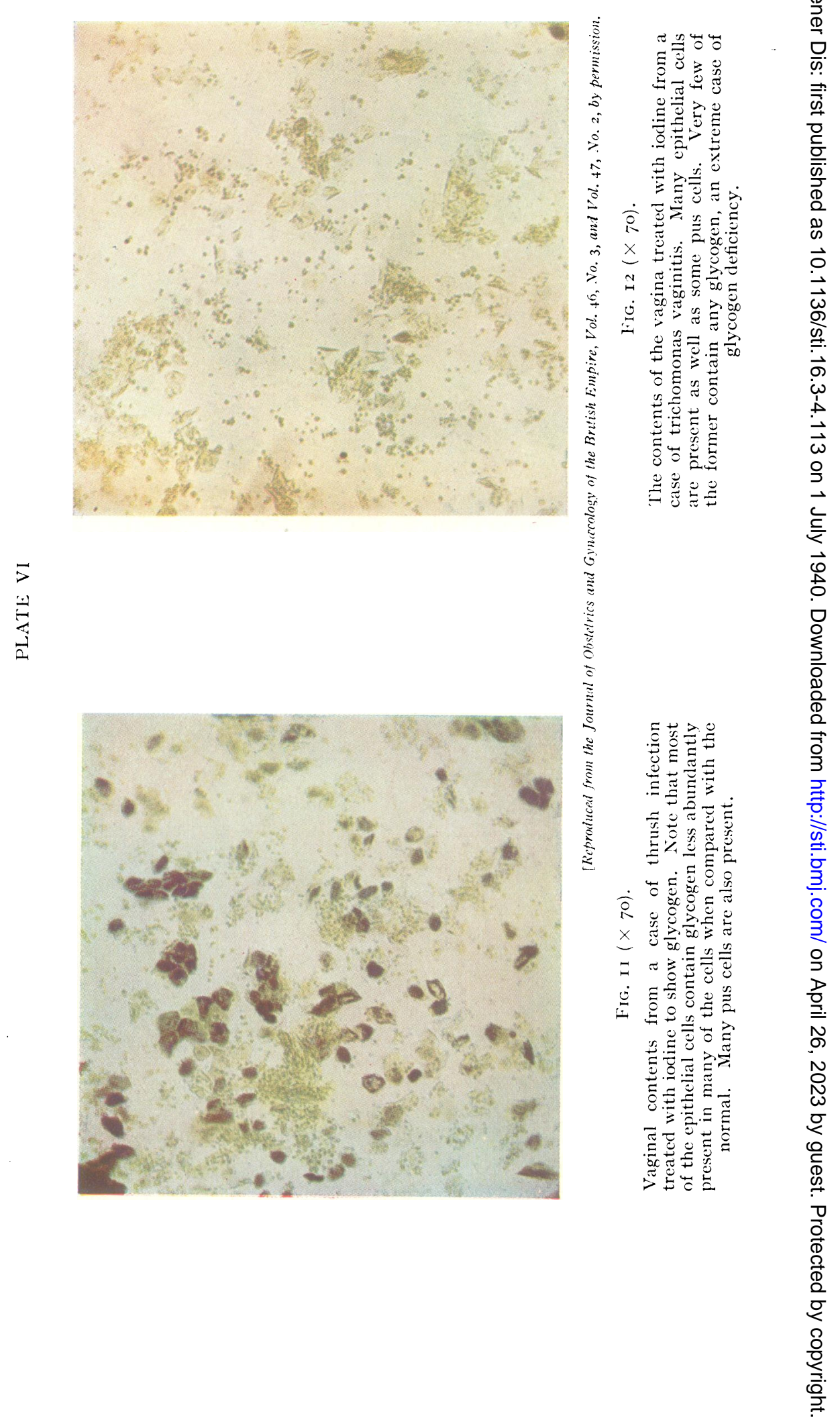


\section{TRICHOMONAS VAGINALIS INFESTATION}

under the microscope in the manner already described. The proportion of epithelial cells to pus cells is noted, unusual parasites such as trichomonas and the thrush fungus are sought for, and the character of the bacterial flora may be roughly defined.

These features are also seen in the stained films which by this time should be ready for examination. The films made from the vagina in particular determine the character of the bacterial flora which may be graded according to the types described, and if a $p \mathrm{H}$ reading has not been taken this grading of the bacterial flora may serve as a rough measure of the acidity of the vaginal contents. Trichomonas should be looked for in the films stained by Leishman's stain and the pseudo-mycelium and blastospores of vaginal thrush in those stained by Gram's method. This examination serves as an excellent control on the wet film examination.

The urethral and cervical films stained by Gram's method are particularly useful for the recognition of gonococcal infection. Normally neither of these films should show many pus cells if care has been taken to avoid contamination from the vagina when making the films. If pus cells are present a diligent search for gonococci and for trichomonas should be made, but the presence of other organisms such as staphylococci or streptococci as a cause of inflammation should not be overlooked.

Examinations in certain clinics by the routine methods just described have shown that trichomonas infestation of the vagina is frequently encountered and less often the urethra is also found to be infested.

My first investigation was carried through with the assistance of my son, Dr. W. A. Liston, in Dr. Haultain's gynæcological clinic. The patients attending this clinic suffered from a great variety of clinical conditions. Among I50 were 26 with $T$. vaginalis, approximately I patient among every 5 examined (Liston and Liston).

The next investigation was made with the assistance of Dr. Murrell in a more selected group of cases in a venereal diseases clinic for women. Two hundred women were examined and as many as 98 were found infested with $T$. vaginalis, that is almost every alternate case ; $5 \mathrm{I}$ of these cases also suffered from gonorrhœa (Liston and Listọn). 


\section{BRITISH JOURNAL OF VENEREAL DISEASES}

The third investigation was made with the assistance of Dr. Lewis Cruickshank in another selected group of women, namely pregnant women suffering from leucorrhœa. Two hundred women were examined and 75 of them harboured $T$. vaginalis. In this group only I of the cases showed also the presence of gonococci (Liston and Cruickshank).

It is thus evident that $T$. vaginalis is very frequently found in the vaginæ of women suffering from a discharge ; it is in fact the commonest cause of leucorrhœa.

The extent to which males may suffer from $T$. vaginalis infestation was determined in an investigation made with the assistance of Dr. Robert Lees, when 400 male patients (excluding cases of syphilis) attending a venereal diseases clinic were examined. Among these 400 patients I6 were found to harbour $T$. vaginalis in some part of the urogenital tract. In all these cases except I the only apparent cause of the discharge was the presence of trichomonas; in the one exception gonococci were also present (Liston and Lees).

\section{Symptoms of $\mathrm{T}$. vaginalis Infestation}

Trichomonas infestation is often accompanied by quite definite clinical characteristics.

In females the disease can assume three forms, an acute, a subacute and a chronic or latent form. The acute form is often mistaken for gonorrhœea. The patient complains of irritation, dysuria, frequency and a copious discharge. Tenderness of the vulva causes difficulty in walking or in sitting down. On inspection the vulva is uniformly reddened and there may be marked œdema of the labia minora. Small slightly raised intensely red papillæ may be seen in the neighbourhood of the urethra and hymen or carunculæ myrtiformes. The discharge is copious, creamy in consistence, and greyish yellow in colour ; it is seldom mucoid unless complicated by other conditions, such as gonorrhœa. The discharge may be frothy but this is not a constant feature. The insertion of a speculum in the acute stage may be very painful, but if a view of the walls can be obtained they will be found to be diffusely reddened, and punctate slightly raised hæmorrhagic spots will be seen especially in the posterior fornix where the discharge accumulates. 


\section{TRICHOMONAS VAGINALIS INFESTATION}

The most acute cases occur in virgins or in parous patients.

In the subacute form of the disease, which may follow the acute phase, the diffuse inflammation subsides but patchy areas of inflammation remain around the ureteral orifice and introitus. In the vagina the inflammatory changes are mainly confined to the vault where punctate raised hæmorrhagic spots still persist. The discharge is less profuse but has similar characteristics to those found in the acute phase. The patients suffering from the subacute form of the disease may or may not complain of any of the symptoms noted under the acute form.

In the chronic or latent form of the disease a superficial examination may reveal little which can be regarded as abnormal. There may be a scanty discharge but when this is examined microscopically it is found to contain many pus cells, and the bacterial flora is either of Type II or Type III. On close inspection, especially at the vault, evidence of patchy inflammation will be found generally, and the vagina and vaginal surface of the cervix may be roughened or granular, a condition easily detected by the examining finger in the vagina.

Trichomonas vaginitis does not always start as an acute infection. The intensity of the disease depends to a large extent on the $p \mathrm{H}$ of the vaginal contents.

While a correct diagnosis can be made often by a careful clinical examination, it is essential to confirm the diagnosis by a microscopical demonstration of the trichomonas.

\section{Principles of Treatment}

It is not possible in the time at my disposal to say much about the treatment of this condition. The disappearance of $T$. vaginalis from the vagina is followed by the cessation of the symptoms of the disease provided always that, with the disappearance of the parasites, glycogen is again deposited in the epithelial cells and Doederlein's bacillus is once more established in the vagina. It is in these circumstances that the vaginal contents acquire a $p \mathrm{H}$ of between 3.8 and 4 . When this is attained $T$. vaginalis can no longer live in the vagina.

It is evident then that the treatment of trichomonas vaginitis must aim not only at destroying the parasites 
(this can be accomplished by the use of a very large variety of preparations) but must be directed to restoration of the glycogen to the epithelial cells and the establishment of Doederlein's bacillus in the vagina. In attempting to destroy the parasites we have to remember that drugs which can kill trichomonas when freely exposed to their action may fail to destroy them when protected beneath the epithelium. We must remember also that trichomonas may find shelter from the drugs in the glands about the vulva. The frequency of relapses in treated cases may be accounted for in this way.

We must remember also that the deficiency of glycogen in the vaginal contents may be due to two causes. First this may be due to an inherent defect in the patient to accumulate glycogen in the epithelial cells probably caused by some endocrine dyscrasia. Secondly to the destruction of glycogen by the trichomonas which apparently feed upon it. When the deficiency in the glycogen of the vagina is due to this latter cause that substance may appear again rapidly in the epithelial cells when the trichomonads are destroyed by, e.g., carbarsone or some other preparation. Cases of this type are cured readily. Those which suffer from an endocrine dyscrasia are not so readily cured for we know very little yet about the conditions which influence the deposition of glycogen in the epithelial cells of the adult female, but the administration of œstrogen may have some effect in this direction.

We are still more ignorant of the circumstances which affect the growth and development of Doederlein's bacillus, although recently some work on other lactic acid producing organisms has suggested that vitamin $B_{1}$ may stimulate it.

Much work on these lines remains to be accomplished before the treatment of trichomonas vaginitis can be regarded as satisfactory. Meanwhile the best guide to the progress of treatment consists in taking the $p \mathrm{H}$ of the vaginal contents at repeated intervals and in observing the amount of glycogen in the epithelial cells and the character of the bacterial flora of the vagina. An examination of this nature is greatly facilitated by using the vaginal pipette already described. A cure is established only when the $p \mathrm{H}$ returns to and remains at about 4 , that is when glycogen will be abundantly present in the 


\section{TRICHOMONAS VAGINALIS INFESTATION}

vaginal epithelium and Doederlein's bacillus will again have been established in the vagina.

The following cases which were seen after the demonstration on which this paper is based may serve to illustrate a number of the points discussed in it ; they are typical examples of large numbers which have been examined in a similar way. They were under the care of Dr. Chisholm to whom I am indebted for the notes.

They are of two main types: (I) A chronic relapsing case like the majority of the cases which have come under our observation; (2) two cases which appear to have been treated successfully.

I am indebted to Dr. Kermack and his assistants for the estimation of lactic acid in the vaginal contents. We hope to be able, in the near future, to publish an account of the method by which this estimation has been made.

A Typical Chronic Relapsing Case.-This is by far the commonest type of trichomonas vaginitis met with among pregnant women. Many similar cases came under our observation.

Case 3ro.-The patient is 24 years old and has been married for some years. Her husband is unemployed; he suffers from some spinal trouble. She is a delicatelooking woman who has suffered much from sickness since her pregnancy began six weeks ago. She complains of a fairly abundant foul-smelling discharge which has troubled her from time to time since the birth of her first child some five years ago. She has been several times in hospital for treatment of the discharge. About four years ago a $D$ and $C$ operation was performed. She has been treated also by district nurses with douches. She complains of no dysuria or frequency but there is some irritation and the parts are red and sore, but not itchy. The discharge becomes worse on walking. She sleeps well. Expected date of delivery, October IIth. She came under observation on I.3.40. Examination revealed nothing noteworthy about the urethra. The orifices of both Bartholin glands were redder than normal. The vagina showed some slightly raised patches and the cervix was red and rough. There was a considerable amount of discharge in the vagina. No gonococci were found in the urethral or cervical films. The vaginal films showed pus cells in larger numbers than epithelial v.D.

I39

$\mathbf{L}$ 


\section{BRITISH JOURNAL OF VENEREAL DISEASES}

cells. Glycogen was markedly deficient in the epithelial cells as revealed by the iodine test. Numerous trichomonas were present. The bacterial flora was of Type III and the $p \mathrm{H}$ of the vaginal contents was 5.53 . There was no evidence of the presence of the thrush fungus. The diagnosis of trichomonas vaginitis having been made by a direct film examination, a suppository of carbarsone ( 2 gr.) was inserted into the vagina and the patient was given four similar suppositories to take home, one to be inserted by herself each day for four days; she was instructed to return in a week.

8.3.40.-Films were again taken from the urethra and cervix. with a view to excluding the possibility of the presence of gonococci. Blood was also taken for a Wassermann test and a gonococcus complement fixation test. All these tests proved to be negative. A carbarsone pessary was inserted and the patient was given four more to take home.

I2.3.40.- On the twelfth day after treatment was begun the discharge was no longer troublesome. Films made at this time showed that epithelial cells were more numerous than pus cells, and no trichomonas were found. Treatment was discontinued and she was to return in a week for re-examination.

I9.3.40.-Examination showed that although a Doederlein flora preponderated in the vaginal film there were a few trichomonas. Treatment with carbarsone pessaries was resumed on the same lines as previously. As she was looking very pale and thin and because her husband was unemployed and unable to provide adequate food she was given a note to the Unemployed Assistance Board (U.A.B.) for extra food. This consisted of one egg daily, some milk, and fruit, and these supplies of extra nourishment were provided for fourteen days.

26.3.40.-A few trichomonas were still present, and treatment with carbarsone was continued as before. The $p \mathrm{H}$ of the vaginal contents was now $4 \cdot 98$. Lactic acid was present to the amount of 0.33 per cent.

2.4.40.-Examination on this day showed epithelial cells more numerous than pus cells and glycogen was abundantly present in the epithelial cells. An almost pure Doederlein flora was established; the $p \mathrm{H}$ was $4 \cdot \mathrm{I} 8$ while lactic acid showed the very high figure of $0.5 \mathrm{I}$ per cent. She seemed to be cured, and treatment with 


\section{TRICHOMONAS VAGINALIS INFESTATION}

carbarsone was discontinued. She was given another note to the U.A.B. for another week of extra food and was told to report again in a fortnight.

r6.4.40.-Examination on this day again showed the presence of trichomonas; the $p \mathrm{H}$ of the vaginal contents was now 4.7 and lactic acid had fallen again to 0.18 per cent. Treatment with carbarsone was resumed as before. To report again in a fortnight.

30.4.40.-One or two trichomonas were seen. Treat-

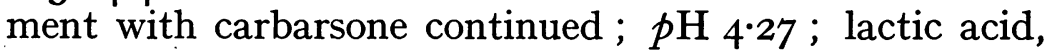
0.31 per cent.

I4.5.40.- Trichomonas were present, and in addition the fungus of thrush was also found. The $p \mathrm{H}$ was 4.32 and the lactic acid, 0.32 per cent. Gentian violet, 2 per cent., was applied to the interior of the vagina as well as to the vulva. The usual treatment with carbarsone was continued, namely one pessary was inserted and the patient was provided with four to be used at home.

28.5.40.-The treatment with gentian violet seemed to have cleared up the thrush infection, but some trichomonas were still present. Epithelial cells were more numerous than pus cells and glycogen was fairly abundantly present in them. The $p \mathrm{H}$ at this time was $5 \cdot 22$. As her diet was deficient she was given a note to the Health Department to be provided with a tin of Bemax. Treatment with carbarsone was continued as before and she was told to return in a week.

4.6.40.- She seemed to be much better. Epithelial cells were more numerous than pus cells and glycogen was abundantly present. The $p \mathrm{H}$ was now $4 \cdot \mathrm{I} 9$. No parasites were found; she appeared to be cured but was asked to return in a fortnight. All treatment was discontinued.

I8.6.40.- She said that she was feeling much better. She has been taking Bemax, but in insufficient quantity. Trichomonas were again found, and the $p \mathrm{H}$ was now $5 \cdot 32$. Treatment with carbarsone was resumed as before.

26.6.40.-In the absence of Dr. Chisholm on holiday she came under the care of another doctor who found epithelial cells more numerous than pus cells; the bacterial flora was of Type II, no trichomonas were found, nor was the thrush fungus demonstrated. She was treated with I per cent. gentian violet and with 


\section{BRITISH JOURNAL OF VENEREAL DISEASES}

stovarsol tablets. One was inserted and two more given to her to use at home.

9.7.40.-The same treatment was continued.

I6.7.40.-Gentian violet, I per cent., and stovarsol tablets.

30.7.40.-Dr. Chisholm returned on this day. The discharge now showed pus cells more numerous than epithelial cells. Trichomonas were again present. A carbarsone pessary was inserted and she was instructed to return on 2.8.40.

2.8.40.-Pus cells more numerous than epithelial cells. Trichomonas again present. Carbarsone treatment resumed, one pessary inserted and five given to her for use at home. The $p \mathrm{H}$ of the vagina was now 4.78 . She was given a note to obtain extra diet. After five months of treatment she remains much in statu quo ante. Treatment relieves the symptoms but the trouble recurs on discontinuing it.

The following are 2 cases which seemed to be cured by treatment. They were not kept under observation for a long period but it is possible that they would have returned if the symptoms had recurred.

Case 349.-This woman was aged 20 years and had been married about nine months; she had never had any children. She complained of a discharge since she had been married and it was gradually becoming worse. It was yellow and foul-smelling and troubled her most if she had to walk any distance, when it ran down her thighs. There was no dysuria but frequency caused her to get up four times during the night. She felt very thirsty. There was some irritation, the parts were red, sore, and itchy and this kept her from sleeping.

29.3.40.-Examination showed that the vagina was congested and contained a yellow frothy discharge. The cervix appeared to be healthy. Pus cells preponderated over epithelial cells in films. Type III flora was present. Glycogen was very deficient in the epithelial cells. Trichomonas were present. The $p \mathrm{H}$ of the vaginal contents was 4.56 ; lactic acid, 0.24 per cent. The diagnosis having been established by direct films, a carbarsone pessary was inserted into the vagina and the patient was given four more pessaries to take home with her, one to be inserted into the vagina each day by herself.

5.4.40.-Examination to-day showed the usual increase I 42 


\section{TRICHOMONAS VAGINALIS INFESTATION}

in the proportion of epithelial cells to pus cells which follows treatment with carbarsone pessaries. No trichomonas were found. She was instructed to return after a week.

I2.4.40.- She looks very well, has no complaints. No trichomonas have been found; $p \mathrm{H}$ of the vaginal contents, 4.32 ; lactic acid, $0 \cdot 3 \mathrm{I}$ per cent.

19.4.40.-Discharged as cured.

Case 357.-Age 22 ; para. I ; expected date of delivery, May 24th. She says that she has suffered from a slight discharge for years. She has been treated for this in the wards of the Infirmary and also by district nurses, who have douched her for a fortnight ; she has also douched herself. The discharge, she says, is white in colour and is foul smelling. It troubles her when she has to walk any distance and then runs down her thighs. She suffers from slight diurnal frequency but sleeps well.

5.4.40.-Examination shows some patchy congestion of the vaginal walls. The vagina contains some creamcoloured frothy discharge. The cervix is rough and shows a number of bleeding points. Pus cells are more numerous than epithelial cells in the direct films made in serum-safranine solution. Trichomonas are present. With the iodine preparation glycogen is slightly deficient in the epithelial cells. The $p \mathrm{H}$ is 4.90 while lactic acid shows 0.22 per cent. Carbarsone treatment as in other cases.

I2.4.40.-A week after treatment was begun direct films showed epithelial cells more numerous than pus cells and already an increase in the number of epithelial cells containing glycogen. The $p \mathrm{H}$ was 5.35 and the lactic acid $0 \cdot 16$ per cent. In spite of the rise in the $p H$ and the fall in lactic acid no parasites have been found. Carbarsone pessaries continued.

I9.4.40.-A week later epithelial cells were still more numerous than pus cells and glycogen abundant in the epithelial cells ; $p \mathrm{H} 4 \cdot 33$, and lactic acid increased to $0 \cdot 3 \mathrm{I}$ per cent., not far removed from normal. No parasites present. Carbarsone pessaries discontinued.

26.4.40.-No complaints ; no parasites found ; discharged as cured.

\section{REFERENCES}

ANDREWS, M. (I929) J.trop. Med., 32, 237.

Bland, P. Brooke, Goldstein, L. \& Weinrich, D. H. (I93i) J. Amer.

med. Ass., 96, 157. 


\section{BRITISH JOURNAL OF VENEREAL DISEASES}

Chatterjee, G. C. (I9I5) Indian med. Gaz., 50, I.

CoRnell, E. L. \& Riba, L. W. (I936) Surg. Gynec. Obstet., 63, $5 \mathrm{II}$.

Cruickshank, R. (I934) J. Path. Bact., 39, 2 I3.

Cruickshank, R. \& Sharman, A. (I934) J. Obstet. Gynac., 41, I90, 208.

Dobell, C. (I934) Parasitology, 26, 53I.

Dobell, C. \& Laidlaw, P. P. (I926) Parasitology, 18, 283.

GANSSLe, H. (I925) Arch.f. Gynäk., 123, 602.

Goodey, T. \& Wellings, A. W. (I9I7) Parasitology, 9, 537.

HEURLIN, M. “ Bakteriologische Untersuchungen der Genitalsekrete der nicht schwangern und nicht puerperalen Frau vom Kindes bis ins Greisenalter unter physiologeschen und gynäkologischepathologeschen Verhältnissen." Berlin, I9I4. S. Karger.

KARNAKY, K. J. (I934) Urol. \& cutan. Rev., 38, I74.

KofoId, C. B. \& SwEZEY, O. "Pentatrichomoniasis in Man." University of California Publication.

LEwIS, B. \& CARROLL, G. (I928) J. Urol., 19, 337.

Liston, W. G. \& Liston, W. A. (I939) J. Obstet. Gynac., 46, 474.

Liston, W. G. \& Cruickshank, L. G. (I940) J. Obstet. Gynac., 47, 109.

Liston, W. G. \& LeES, R. (I940) Brit. J. vener. Dis., 16, 34.

Lynch, K. M. (I922) J. Amer. med. Ass., "79, II30.

Nitschke, P. H. (1936) J. Amer. med. Ass., 107, I2.

Oberst, F. W. \& Plass, E. D. (I936) Amer. J. Obstet., 32, 22.

Pöwell, W. N. (I936) Amer. J. Hyg., 24, I45.

Rosenthal, D. B. (I93I) Med. J. Aust., 1, 782.

Schultheiss, H. (I929) Arch. f. Gynäk., 136, 66.

Stableforth, A. W., Scrogie, N. J. \& Gould, G. N. (I937) Vet. Rec.,

Visher, J. W. (I929) J. Amer. med. Ass., 92, 2098.

49, 2 II.

WAGNER, O. \& HeES, E. (I937) Zbl. f. Bakt., 138, 273.

WenRich, D. H. \& Emmerson, M. A. (I933-34) J. Morph., 45, I93.

Wenyon, C. M. (r926) Protozoology, 1, 654, 660. 